\title{
Increasing use of the IUD through community and clinic based education activities in rural Honduras
}

Ivo Flores Flores

Elida Rosa Aguilar Fonseca

Rosa Merlen Flores

Ricardo Vernon

Population Council

Jorge Solorzano

Population Council

See next page for additional authors

Follow this and additional works at: https://knowledgecommons.popcouncil.org/departments_sbsr-rh

Part of the International Public Health Commons, Maternal and Child Health Commons, Public Health Education and Promotion Commons, and the Social and Behavioral Sciences Commons How does access to this work benefit you? Let us know!

\section{Recommended Citation}

Flores, Ivo Flores, Elida Rosa Aguilar Fonseca, Rosa Merlen Flores, Ricardo Vernon, Jorge Solorzano, Suyapa Pavón, Marco Tulio Falck, and Alba Lidia Sanchez. 2007. "Increasing use of the IUD through community and clinic based education activities in rural Honduras," FRONTIERS Final Report. Washington, DC: Population Council. 
Authors

Ivo Flores Flores, Elida Rosa Aguilar Fonseca, Rosa Merlen Flores, Ricardo Vernon, Jorge Solorzano, Suyapa Pavon, Marco Tulio Falck, and Alba Lidia Sanchez 


\title{
Increasing use of the IUD through Community and Clinic based Education Activities in Rural Honduras
}

\author{
Department of Integral Health Care \\ Ministry of Health, Honduras \\ Ivo Flores Flores \\ Élida Rosa Aguilar Fonseca \\ Rosa Merlen Flores \\ Frontiers in Reproductive Health Program, Population Council \\ Ricardo Vernon \\ Jorge Solorzano \\ ASHONPLAFA \\ Suyapa Pavón \\ Marco Tulio Falck \\ EngenderHealth \\ Alba Lidia Sánchez
}

November 2007

This study was made possible by the generous support of the American people through the United States Agency for International Development (USAID) under the terms of Cooperative Agreement No. HRN-A-00-98-00012-00 and Subaward No. AI04.46A. The contents are the responsibility of the FRONTIERS Program and do not necessarily reflect the views of USAID or the United States Government.

\section{(2) Population Council FRONTIERS}




\section{SUMMARY}

Women in rural areas of Honduras are less likely to use the IUD than any other method. In 2001, the contraceptive prevalence rate in urban areas was $70 \%$, but only $57 \%$ in rural areas. An even larger proportionate discrepancy was found for the IUD - in urban areas it was used by 15 percent of married women and only five percent in rural areas. Over the last few years, the Honduran Ministry of Health has conducted extensive IUD training programs for providers to try to increase its availability in rural and semi-rural areas, but studies have shown that clients and community members continue to have little information on this method.

This document presents the results of an operations research project implemented by the MOH in Honduras with the technical and administrative assistance from the Population Council's Frontiers in Reproductive Health (FRONTIERS) Program, ASHONPLAFA and EngenderHealth, and funding from USAID. This project tested a strategy to inform communities about the availability of the IUD in nearby health centers and about the method's most salient attributes. To evaluate the strategy's effect on increasing knowledge about, and use of, the IUD, an experimental pretest/post-test design with a control group was used, in which 41 health centers in 18 municipalities were randomly assigned to either the experimental or control group. In the experimental group, providers were trained to conduct client and community information activities and provided with a set of informational materials including: 1) a manual for communicating information about reproductive health services; 2) an instructional flyer for interested persons; 3 ) a brochure explaining the characteristics, advantages and disadvantages of the IUD; and 4) a double-letter-sized poster highlighting the key characteristics of the method. Training workshops were conducted in August 2005 and the strategies implemented from October 2005. January to September 2005 was considered the pre-intervention period and October 2005 to May 2006 the post-intervention period. To control for possible seasonal effects, service statistics for the January-May 2005 and 2006 periods were also compared.

Use of simulated clients before and after the intervention showed that its introduction did not bias delivery of family planning services, nor did it limit users' free and informed choice. Counseling post-intervention was found to be of a higher quality as a consequence of quality control reinforcement during training workshops. In the experimental group, the monthly average of IUDs delivered by the health center doubled from 1.12 to 2.0, whereas in the control group it decreased from 1.72 to 0.78 . These results imply that if the strategy were expanded to all $1,108 \mathrm{MOH}$ health centers in Honduras, the annual number of IUD acceptors could possibly increase from 11,500 to about 20,000 IUD new users. When correlating the intensity with which the centers implemented the communications strategy with use of the IUD, those that implemented the strategy with a high intensity increased their monthly averages by 1.27 IUDs compared with an increase of 0.45 among those that implemented the strategy with a low intensity. Clinic records show that the strategy attracted women who had less schooling, a greater number of children, who took longer to reach the health center, and who had never used a contraceptive method, compared with women in the control group.

The results were presented in all health areas that receive USAID support. The IEC materials have been reproduced and used in new sites. In addition, a large proportion of health centers and health zones included the strategy in their 2007 workplans and are now implementing it. 


\section{CONTENTS}

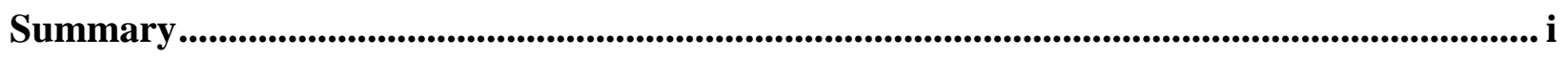

Background ...................................................................................................................................... 1

Problem statement and intervention to be tested............................................................................... 2

Objectives and Hypotheses.................................................................................................................... 3

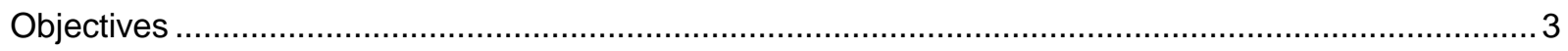

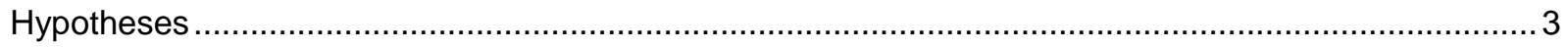

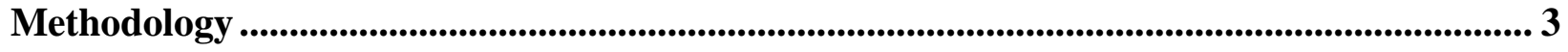

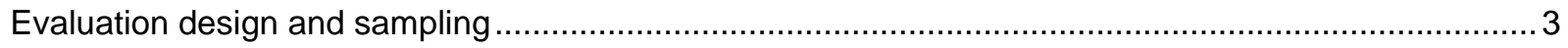

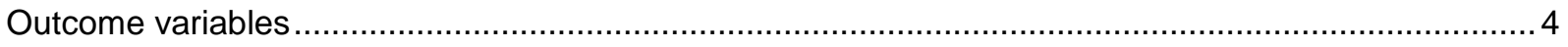

Intervention Implementation ...................................................................................................... 5

Information, Education and Communication (IEC) materials ……...............................................

Training of Trainers and Service Providers ................................................................................

Monitoring and Supervision in the CESAR and CESAMOS ........................................................ 6

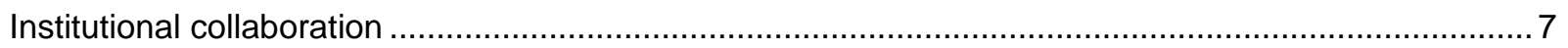

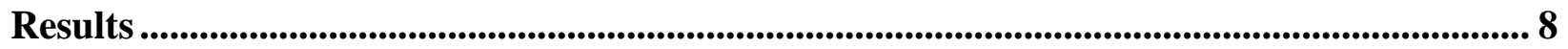

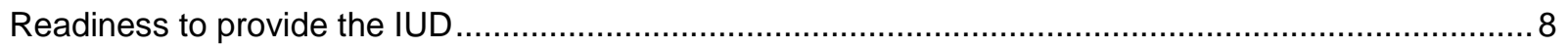

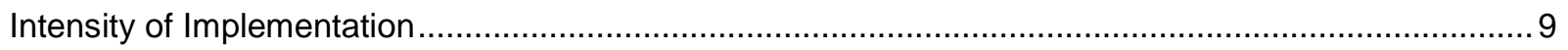

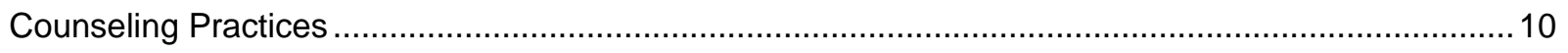

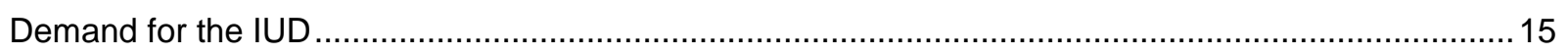

Socio-demographic characteristics of IUD Acceptors ………………………………………..... 18

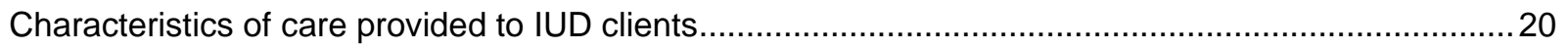

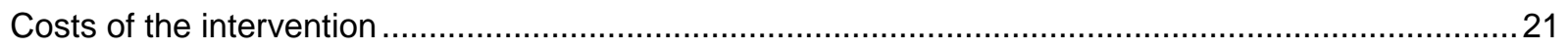

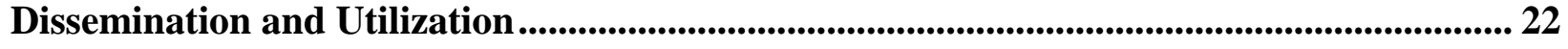

Conclusions and Recommendations............................................................................................... 22

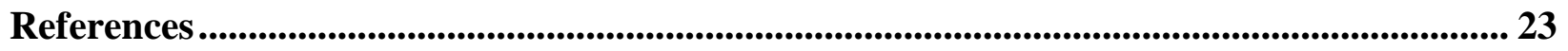

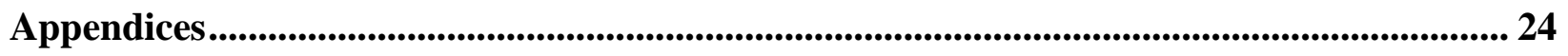

Appendix 1: Health Units Included in the Sample by Group, Department and Municipality.............224

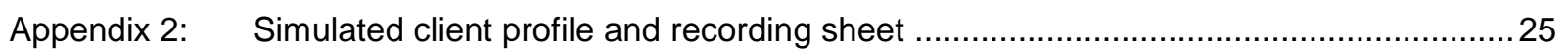

Appendix 3: Questionnaire for Women accepting an IUD ……...............................................29

Appendix 4: Educational activities by Experimental Clinic ……….................................................30 


\section{BACKGROUND}

According to the Encuesta Nacional de Epidemiología y Salud Familiar 2001 (National Epidemiological and Family Health Survey or ENESF for its acronym in Spanish) in 2001, 62 percent of married women of fertile age in Honduras used a contraceptive method. The most widely used method (18\%) was sterilization, and 9.6 percent used the IUD. While the contraceptive prevalence in urban areas was 70\%, in rural areas it was only $55 \%$. Differences in use of the IUD were also found between urban and rural areas, with women in urban areas three times $(15 \%)$ more likely than those in rural areas $(5 \%)$ to use the method. This proportionate difference is greater than for other contraceptive methods, for which the ratio between urban and rural areas is never greater than 1.5 to 1 .

The Honduran Ministry of Health $(\mathrm{MOH})$ provides primary health care services through two types of health units: health centers in urban areas (Centros de Salud Médicos Odontológicos or CESAMOS), which have at least a doctor, a dentist, a nurse, a nurse auxiliary and a health promoter, and serve populations with over 6,000 inhabitants; and rural health posts (Centros de Salud Rurales or CESARES), which have a nurse auxiliary only and usually serve communities with populations between 1,500 and 3,500 inhabitants. The MOH has 241 CESAMOS and 867 CESARES.

Nurse auxiliaries are women who have one year technical training following completion of a minimum of three years of secondary school. The main services provided by auxiliaries include vaccinations, child growth and development monitoring, pre and postnatal care, and the prevention and treatment of respiratory and diarrhea-related illnesses. They prescribe antibiotics for cases clearly defined in the service delivery guidelines and they refer complicated cases to health providers that are better equipped to handle more serious cases.

Before 1998, nurse auxiliaries were only authorized to distribute condoms and contraceptive pills to continuing users but not to new pill users, who had to first be prescribed the method by a doctor or a professional nurse. Several studies had shown that paramedical health agents could provide good quality IUD services and increase access to the method (see, for example, Akin, Gray and Ramos, 1980; Eren, Ramos and Gray, 1983; Zeighami et al, 1976; Bang, Song and Choi, 1968). Consequently, through the Council's USAID-funded operations research program, the $\mathrm{MOH}$ conducted a study to test whether nurse auxiliaries could safely provide IUD services, DMPA injections, and take vaginal cytology samples of proper quality. The results showed that auxiliaries gave their clients the appropriate information, complied with the service delivery guidelines, and followed them up appropriately (Villanueva et al, 1998). Based on these results, in 1999, the MOH modified the official Service Delivery Guidelines for Integral Care for Women and explicitly authorized nurse auxiliaries to provide IUDs and injections, and to take vaginal cytology samples (MOH, 1999). A second OR study conducted between 1999 and 2001 with nurse auxiliaries showed that these positive results were still achieved even when training was expanded to a much larger number of nurse auxiliaries (Villanueva et al, 2001).

Since 2002, and with support from EngenderHealth with USAID funding, the MOH has continued to train nurse auxiliaries in the country's six health regions using a training model similar to the one developed through the OR projects. This model consists of a five-day theorybased group training, with refresher contents on contraceptive methods and counseling of 
patients, as well as infection prevention procedures ${ }^{1}$ and practical sessions using pelvic models for building skills in IUD insertion and removal. The training is then followed up by at least three supervised insertions in a service delivery unit with a large number of IUD patients. Trainers evaluate quality during insertions using a structured observation list. If the quality is considered appropriate, the nurse auxiliary is certified to insert IUDs. The sector nurse then has to visit the auxiliary and observe at least one insertion (and when possible, one removal) to verify technical competence on site, although this does not happen all the time. All those who enter the IUD training will have previously had one week training in counseling ${ }^{2}$.

In 2003, EngenderHealth and the MOH undertook a qualitative follow up study in three health regions in which nine program managers at different levels, 11 sector nurses, 43 family planning clients and 20 nurse auxiliaries that had been trained to provide IUD services were interviewed (Martínez, 2003.) The study showed that only 13 of the 20 nurse auxiliaries offered IUD services to their clients. The main reasons for not providing the service were lack of confidence in their skills, lack of equipment at the facility, and lack of demand from clients. Those who had inserted more than 50 IUDs since training attributed their success to good counseling of clients, raising awareness about the method among clients and in the communities through volunteer educators, and asking satisfied users to refer new clients. All auxiliaries felt that their training in counseling had been good, and had positive opinions about their IUD training. To increase use of the IUD, the auxiliaries recommended improving awareness-raising activities through a variety of channels, including training community health workers, providing IEC materials, discussing the method during family planning counseling, and mentioning it to clients coming for other services. One third of the 43 family planning clients interviewed believed at least one of the rumors they had heard about the IUD, which demonstrated the need for providing technically accurate information on the method to potential clients.

\section{PROBLEM STATEMENT AND INTERVENTION TO BE TESTED}

The challenge to implementing the recommendations of the EngenderHealth evaluation was to find strategies that could be easily implemented at the community level within resources available to the MOH. In 2001, the MOH and FRONTIERS had carried out a small operations research study in six experimental and six control health centers to see if a ten-minute talk by a nurse auxiliary and handing out of an informational flyer about the availability of the IUD, DMPA and Pap smears increased demand for these services. Women were also asked to give flyers to relatives and friends who might be interested in these services. The mean monthly number of IUD insertions increased from 2.8 to 4.5 in the experimental group and decreased

\footnotetext{
1 Infection prevention includes: washing hands, antiseptics and disinfectants, use and elimination of sharp objects, processing instruments and other elements, waste disposal, decontamination and preparation of chlorine solutions, cleaning of instruments and other elements, sterilization and stock keeping, cleaning of the facility.

2 This training includes the concept of reproductive health, sexual and reproductive rights, gender and equity, contraceptive methods, myths and barriers to contraception, introduction to counseling: informed consent and user rights; values and attitudes; communication techniques; types of communication; The GATHER counseling interview; counseling for voluntary surgical contraception and special cases: men, single adolescents, postpartum and postabortion; counseling work-plans.
} 
from 1.4 to 0.9 in the control group; the monthly average of DMPA users and of Pap tests also increased significantly (Mendoza and Vernon, 2001). This study suggested that simple facilitybased interventions can increase the demand for new services in health centers and posts. On this evidence a similar intervention, focused on increasing awareness about the IUD, was developed and tested.

\section{OBJECTIVES AND HYPOTHESES}

\section{Objectives}

1. To design a model for increasing information about new reproductive health services in rural and semi-rural communities in Honduras.

2. To test the effectiveness and cost-effectiveness of the model in increasing awareness of and demand for the new services.

\section{Hypotheses}

- Training in information-giving about the IUD will not produce bias during client counseling in favor of the IUD, and will improve the quality of counseling through providing more complete information on different contraceptive methods.

- Areas in which the communication strategy is introduced will have a greater increase in women choosing to use the IUD than in areas without the communications strategy.

\section{MeThODOLOGY}

\section{Evaluation design and sampling}

An experimental pre-intervention / post-intervention design with a control group was used:

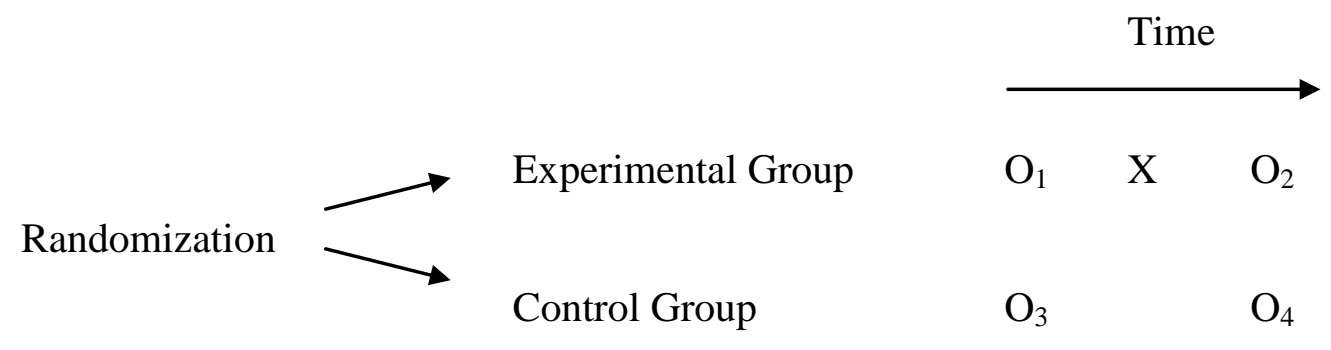

Where $\mathrm{O}_{1}$ and $\mathrm{O}_{3}$ are pre-intervention measures of the key outcome indicators, $\mathrm{X}$ is the intervention, and $\mathrm{O}_{2}$ and $\mathrm{O}_{4}$ are the post-intervention measures of the outcome indicators. To select the sample, a brief diagnostic study was undertaken in 18 municipalities of seven departments. Service providers and/or their supervisors were asked if the health facilities in these 
municipalities met four inclusion criteria: 1) having personnel trained in IUD insertion; 2) having complete IUD insertion equipment; 3) having inserted or removed at least one IUD in the past 12 months; and 4) having been trained in contraceptive counseling and in the prevention of infections. In total, 41 facilities were reported to meet these criteria and so were included in the study. However, in pre-intervention supervision visits it was observed that five of these units in two municipalities did not meet the inclusion criteria and thus they were substituted by two municipalities in the same Departments and a similar number of health centers.

To avoid possible contamination between health facilities through staff interacting during their monthly meetings, all facilities in a given municipality were assigned to either the control or the experimental group. Municipalities were paired according to the number of facilities they had (the pair with most facilities, the following pair, etc.) and municipalities from each pair were randomly assigned to either the experimental or control group (see Appendix 1 for a listing of municipalities and health facilities). The sample was also balanced in terms of the types of facilities, with 13 rural health centers (CESARES) and seven urban health centers (CESAMOS) in the control group, and 12 CESARES, 7 CESAMOS and two Maternal-Child Health Units in the experimental group.

\section{Outcome variables}

The interventions were compared and evaluated in terms of the following outcome variables:

- Quality of counseling for women that request family planning services. This variable was measured using simulated clients acting out a predefined role and describing the experiences through a written report using a code sheet. The scripts and code sheets of simulated clients are presented as Appendix 2.

- Monthly average number of women using an IUD. This information was obtained from the AT1 form or the Record of Primary Care kept by service providers.

- Socioeconomic characteristics of women using an IUD. This information was obtained through a questionnaire that providers administered to women who requested an IUD (see Appendix 3).

- Cost per additional IUD user: this cost was obtained by using the project's accounting records. The cost per additional user was estimated by adding the total provider training costs, including financial costs (travel expenses and per diem of participants, other training expenses and the cost of the design and reproduction of IEC materials) plus the non-financial costs represented by the time used by $\mathrm{MOH}$ personnel to implement information activities (inform users, distribute materials, train promoters) and in supervising the project's activities. This sum was divided by the additional number of users generated by the strategy, which was estimated by subtracting the difference of the post averages minus pre-intervention of the experimental group minus the control group. 


\section{INTERVENTION IMPLEMENTATION}

The intervention consisted of providing additional information about the IUD at the clinics through:

- Handing out flyers and brochures to clients for their own use and to give to their friends;

- Mentioning availability of the IUD to all clients that visit the health center;

- Ensuring complete information is given about the method during family planning counseling;

- Providing information about the IUD during health talks in the community and through displaying posters about the method in public places.

\section{Information, Education and Communication (IEC) materials}

The materials used were adapted primarily from materials developed in Guatemala during a project to re-launch the IUD. These materials were reviewed and adapted to Honduran language and culture by a technical team comprising staff from the MOH National Women's Program, EngenderHealth and FRONTIERS. The revised versions of each material were pre-tested with 8 to 12 providers and health center clients in the participating areas. These were the following:

- Manual for informing clients about the IUD. This manual for service providers suggests ways of informing clients about the availability of the IUD in the health center and of training volunteers to inform communities about the method. One hundred copies of this manual were printed and one copy was given to each service provider in participating clinics.

- Posters: a double-letter sized color poster was produced. The poster underlines seven significant attributes of the IUD (e.g. it provides 10 years protection, can be removed when desired, available at no cost at all health centers), and promotes the healthy timing and spacing of pregnancies between 3 to 5 years. The poster was displayed by health center personnel, volunteers and clients in areas where community members gather. A total of 1,000 posters were printed and approximately 45 copies were given to each participating clinic.

- Flyers: the flyer is a copy of the poster, printed in black and white, and half-letter size. The flyer was distributed through health center clients and health volunteers at each clinic, who were asked to give them to neighbors, relatives and friends who might want to use a longterm family planning method. A total of 25,000 copies were printed and approximately 1,100 copies were given to each health center.

- Brochures: the brochure explains the characteristics, advantages and disadvantages of the method. The brochure was used during family planning counseling sessions and was given to women who showed an interest in the IUD. Five thousand copies were printed and provided to the participating clinics.

\section{Training of Trainers and Service Providers}

Training took place in two stages. During the first stage, teams of trainers in the experimental regions and zones were trained, as well as one or two service providers for the clinics. During the second stage, these teams cascaded the training to all personnel in the experimental clinics 
during their monthly meetings, and later to personnel from each clinic trained as health volunteers.

Three workshops were held in the first stage, each lasting six hours. They were held in August 2005 in the cities of Tegucigalpa, Santa Rosa de Copan and La Ceiba, which are accessible for the zonal teams from the municipalities closest to each city. The workshops were facilitated by personnel from the MOH National Program for Women, and were attended by 9 nurses, 8 nurse auxiliaries and 7 medical doctors from the sector. Results from a simulated client exercise undertaken during the baseline were presented, as well as a review of the basic elements of good counseling, reinforcing good practices with role-playing exercises. Didactic elements of adult education were also presented, IEC materials were provided, and exercises on each of the educational activities were undertaken. Family planning flipcharts were also handed out (developed by the $\mathrm{MOH}$ with the support of EngenderHealth) as support material for family planning counseling.

At the beginning and end of each workshop, questionnaires were given to evaluate learning and satisfaction of the workshop participants. Pre-training, the average score was $78 \%$, and after training the average was $95 \%$. The least known issue was contraindications against the IUD. During the training of trainers' workshop, training workshops were programmed for each of the participating zones throughout the month following the training. Between August and October 2005, however, three hurricanes hit Honduras and the participating clinics had to focus on attending emergencies resulting from the floods, and so most of the workshops were held in October. For the Concepción, Yarumela and El Carril health centers, training consisted only of a short explanation by the zone nurse during supervision visits when they were provided IEC materials for their use. This shortened version was used because of the zone director's wish not to interfere with service delivery.

\section{Monitoring and Supervision in the CESAR and CESAMOS}

MOH personnel took charge of training and supervision in all sites from August 2005. These supervisors found that, after the intervention, three of the clinics in the control group (Lacalí, Montaña Izopo and Cruz Concordia) and eight of the clinics in the experimental group (Los Olanchitos, Nueva Armenia, Concepción, Yarumela, El Ocote, El Nance, Carbajales and La Hicaca) did not have the complete equipment or trained personnel required to perform IUD insertions, and so did not meet the inclusion criteria. In some cases (such as in Concepción) personnel undertook the educational activities and arranged for the municipal supervisor to perform the IUD insertions at a predetermined date; at the Erandique CESAMO, the nurse trained personnel in rural clinics to do the educational activities and then undertook the insertions at the rural clinics, although the insertions were recorded in the CESAMO clinic reports.

According to the $\mathrm{MOH}$ supervisors, the factors that determined which promotional activities were implemented in the health centers were individual providers' attitudes and careful followup of activities by supervisors. For example, in one clinic the staff member that had participated in the training showed no interest in implementing the activities and so during the supervisor's visit, a nurse auxiliary was trained who took on these responsibilities. In another clinic the 
supervisors were not able to motivate the two staff members who had participated in the training workshop during two supervision visits ${ }^{3}$.

Supervisors found differences in the quality of service statistics recorded in the clinics, and at municipal, regional and central levels. The higher the administrative level, the less reliable the service statistics, as there is no mechanism to ensure the quality of the information. Incomplete medical records and follow-up forms were also evident.

Supervisors found that personnel accepted the orientation manual very well, although some doctors complained that it was directed to nurses and auxiliaries and not to them. Other problems identified were that educational materials were handed out without a strategy, rarely trying to segment the public for each kind of material. For example, many women who requested the IUD were not given the counseling brochure as it was being used for community education activities instead. The distribution of materials from municipalities to clinics was slower than expected, but this problem was resolved during supervisory visits.

\section{Institutional collaboration}

The MOH, EngenderHealth, the Population Council's FRONTIERS Program and ASHONPLAFA collaborated to implement this project. Staff of the MOH's Department for the Integral Care of Women organized the training meetings and facilitated the training workshops for staff of the health centers and their supervisors. They also supervised the activities, collected service statistics in health centers, participated in the data analysis and in the preparation of this report, and conducted visits and meetings in Tegucigalpa at project sites and other Departments to disseminate the results of the project.

The Population Council provided technical assistance in the development of the intervention, IEC materials and the development of measurement instruments. It also actively participated in the supervision of the implementation of activities, the analysis of information and the development of technical reports, and facilitated the first training workshop.

ASHONPLAFA was in charge of the management of the project and carried out the simulated client study. It also conducted a large part of the data analysis activities to prepare this report.

EngenderHealth participated in the design of the interventions, carried out the initial diagnostic study in the units, adapted IEC materials and implemented their pre-testing in order to ensure their efficacy. It also played a significant role in the dissemination and utilization of results in a larger number of units and municipalities.

3 A case of 'contamination' occurred when a nurse who worked in one of the control clinics visited an experimental clinic and became so interested that she took materials to begin educational activities in her own clinic, which then became one of the best performers in the control group. 


\section{RESULTS}

\section{Readiness to provide the IUD}

In the first months of 2005, the project coordinator phoned the 41 health centers to ask the staff and their supervisors whether their health center complied with the inclusion criteria (see above). According to the information received, all 41 health centers did comply and so were included in the study.

Table 1: Clinic readiness to provide the IUD

\begin{tabular}{|c|c|c|}
\hline VARIABLE & $\operatorname{CSR}(n=21)$ & CSM/CMI $(n=15)$ \\
\hline$\%$ that offers privacy to users & 100 & 100 \\
\hline$\%$ with infection prevention practices & 94 & 100 \\
\hline \multicolumn{3}{|l|}{ \% with: } \\
\hline - Electricity & 86 & 100 \\
\hline - Water & 95 & 100 \\
\hline - Toilets & 100 & 100 \\
\hline - Towels & 72 & 79 \\
\hline \multicolumn{3}{|l|}{ IUD insertion equipment: } \\
\hline - Speculum & 86 & 100 \\
\hline - Forceps & 76 & 100 \\
\hline - Tenaculum forceps & 67 & 100 \\
\hline - Hysteromenter & 57 & 93 \\
\hline - Stretcher for examination & 81 & 100 \\
\hline - Liquid chlorine & 43 & 73 \\
\hline - Scissors & 76 & 100 \\
\hline - Stainless steel cup & 52 & 87 \\
\hline - Gloves & 86 & 100 \\
\hline - Sheet to cover patient & 52 & 87 \\
\hline \multicolumn{3}{|l|}{ Supplies for Sterilization / Disinfection } \\
\hline - Chlorhexidine & 48 & 40 \\
\hline - Savlon & 24 & 33 \\
\hline - Hibitane & 5 & 40 \\
\hline - Other & 24 & 7 \\
\hline - Any supply & 71 & 73 \\
\hline \multicolumn{3}{|l|}{ Supplies for solid waste } \\
\hline - Black bags & 5 & 7 \\
\hline - Red bags & 51 & 60 \\
\hline \multicolumn{3}{|l|}{ Waste management } \\
\hline -Incineration & 43 & 87 \\
\hline -Landfill & 19 & 40 \\
\hline -Garbage collector & 24 & 20 \\
\hline
\end{tabular}


Once the experiment started, supervisors were requested to fill out a questionnaire to assess the readiness of the sampled health centers to provide IUD services. Unfortunately, only 36 of these records were received or kept on file. During their initial visits, supervisors found that eight of the health centers in the sample (five experimental and three controls) did not comply with the inclusion criteria, most frequently because of a lack of trained staff or equipment to provide services. This was reported to the health area teams, which promised to solve the problems and achieve readiness for providing the IUD services in these eight health centers.

Table 1 shows that all 36 health centers for which data was collected had visual and auditory privacy, and most had implemented infection-prevention practices. They all had toilets and, except for some rural posts, electricity and running water; towels to dry hands were less frequent. All urban health centers had all the essential equipment needed; in rural clinics, however, a significant proportion did not have a hysterometer and a tenaculum forceps. Although most did not have chlorine in stock, the usual procedure was to buy the solution at the nearest store to the clinic. Although there appears to be a shortage of solutions and equipment for disinfecting and decontaminating equipment, the data collection instrument did not record presence of an autoclave, which is the most common means available in these health centers. There was no significant difference between experimental and control groups.

\section{Intensity of Implementation}

To measure the degree to which the interventions were implemented (i.e., the intensity of the interventions), the experimental clinics were requested to keep a special form detailing:

1) Number of clinic clients that were informed about the availability of the IUD in the clinic;

2) Number of flyers, brochures and posters that the clinics distributed through their clients and voluntary health promoters;

3) Number of talks given in the health center;

4) Number of volunteers trained to give information on the IUD in the communities.

The project interventions were implemented between October 2005 and May 2006. Considering that there were 21 clinics in the experimental group and an intervention period of eight months, 168 monthly reports should have been received from all clinics. However, between October and December 2005, the 21 experimental clinics only reported 28 out of a possible 63 months of IEC statistics, whereas 101 out of a possible 105 monthly reports were received between January and May 2006.

Table 2 summarizes the statistics derived from these 129 clinic-month reports. The health centers informed an average of 45 clients per month on the availability of the IUD and distributed through their clients an average of 102 flyers, 29 brochures and 26 posters. They also gave an average of nine monthly talks, trained 2.7 health volunteers per month, and handed out 49 flyers, 6 brochures and 24 posters per month. 
Table 2: $\quad$ Monthly Average and Range of Educational Activities Implemented in the Experimental Clinics during the Intervention Period

\begin{tabular}{|c|c|c|c|c|}
\hline \multirow{2}{*}{ EDUCATIONAL ACTIVITIES } & \multirow{2}{*}{$\begin{array}{l}\text { N MONTHS- } \\
\text { UNIT } \\
\text { REPORTED }\end{array}$} & \multicolumn{2}{|c|}{ RANGE } & \multirow{2}{*}{ MEAN } \\
\hline & & MINIMUM & MAXIMUM & \\
\hline Clients informed on the IUD & 129 & 0 & 234 & 45.40 \\
\hline Flyers distributed to and by clients & 129 & 0 & 536 & 102.65 \\
\hline $\begin{array}{l}\text { Brochures distributed to and by } \\
\text { clients }\end{array}$ & 129 & 0 & 230 & 28.94 \\
\hline Posters distributed to and by clients & 129 & 0 & 225 & 26.36 \\
\hline Talks in health center & 129 & 0 & 61 & 8.97 \\
\hline Trained volunteer promoters & 129 & 0 & 61 & 2.71 \\
\hline Flyers distributed by volunteers & 129 & 0 & 284 & 48.64 \\
\hline Brochures distributed by volunteers & 129 & 0 & 150 & 5.97 \\
\hline Posters distributed by volunteers & 129 & 0 & 102 & 23.86 \\
\hline
\end{tabular}

Appendix 4 presents the total number of educational activities reported by each clinic. To create an index of the intensity with which the intervention was implemented, clinics were ranked according to the values of each variable and the intensity of the intervention by assigning a value of one (the lowest) to the seven health centers with the lowest volume of activities in the variable, of two to the following seven, and of three to the seven clinics with the highest intensity. After ordering all the units according to all the variables, a variable was created by adding the ordinal scores of three variables: informed clients in the clinic; talks given in the clinic; and trained volunteers. An index for effort in the distribution of printed materials was created by dividing by six the sum of the ordinal value of the distribution of flyers, brochures and posters by clients and volunteers, and ordinal scores assigned that added to the sum of the other three variables. The last column of the table in Appendix 4 presents the final ordinal score obtained for each unit and classification of the units in terms of the intensity of the educational activities.

Further proof of the degree to which the interventions were implemented came from the clinical records of IUD acceptors during the intervention period (see section 6.5.). Whereas $49 \%$ of women who requested an IUD in the experimental group were given flyers and brochures to give to friends and relatives in their communities, only $15 \%$ of women in the control group said they had received these materials.

\section{Counseling Practices}

One concern was the possibility that the educational activities may produce a bias in favor of the IUD, which would violate the principle of free and informed choice. To ensure that the educational activities could be carried out without compromising this basic principle, simulated clients made visits before and after training to determine the quality of counseling. In the first round of visits (in June and July 2005), 18 experimental clinics were visited (visits to the remaining clinic could not be completed because staff were not available). The findings were 
presented in the training workshops and appropriate counseling practices were clarified to solve any problems identified. After training, supervisory visits were made in April and June 2006 (although three visits could not be completed).

In both rounds, simulated clients acted the role of a 32-year-old woman with three children who had been using the pill for five months but had strong headaches and wished to use another contraceptive method. The provider's actions were recorded in a code sheet after leaving the health center. Appendix 2 presents the simulated client's profile and the sheet on which they recorded their observations of the interaction. In both rounds of visits, the health staff that attended the simulated clients were mostly doctors and nurse auxiliaries.

Table 3 shows that the degree to which providers in the 18 clinics established interpersonal relationships with the simulated clients did not change after the intervention for any of the indicators measured. For most consultations, the counseling was perceived to be individualized and polite, the provider showed interest, and there were few interruptions, but auditory and visual privacy seem to be lacking.

\section{Table 3: Interpersonal Relationships between Simulated Clients and Providers}

\begin{tabular}{|l|c|c|c|c|}
\hline \multirow{2}{*}{} & \multicolumn{4}{|c|}{ Period } \\
\cline { 2 - 5 } & \multicolumn{2}{|c|}{ Before } & \multicolumn{2}{c|}{ After } \\
\cline { 2 - 5 } & $\mathrm{n}=18$ & $\%$ & $\mathrm{n}=18$ & $\%$ \\
\hline The provider introduced him/herself by name & 2 & 11 & 5 & 28 \\
\hline Counseling was individual & 17 & 94 & 16 & 89 \\
\hline Counseling was interrupted & 4 & 22 & 4 & 22 \\
\hline There were strangers listening to what I said & 2 & 11 & 1 & 6 \\
\hline There were strangers watching me & 4 & 22 & 3 & 17 \\
\hline The provider treated me politely & 17 & 94 & 18 & 100 \\
\hline I felt the provider was interested in my health & 14 & 78 & 15 & 83 \\
\hline The provider seemed annoyed & 2 & 11 & 1 & 6 \\
\hline
\end{tabular}

Table 4 describes the questions that service providers asked to diagnose the clients' needs, and again, there are no significant differences; indeed, the providers were slightly less likely to ask some important questions, such as satisfaction with a method and asking whether the woman wanted to use another one, after the intervention. 
Table 4: Questions Asked by Providers to Diagnose the Needs of Simulated Clients

\begin{tabular}{|l|c|c|c|c|}
\hline \multirow{2}{*}{} & \multicolumn{5}{|c|}{ Period } \\
\cline { 2 - 5 } & \multicolumn{2}{|c|}{ Before } & \multicolumn{2}{c|}{ After } \\
\cline { 2 - 5 } & $\mathrm{n}=18$ & $\%$ & $\mathrm{n}=18$ & $\%$ \\
\hline The provider asked me my age & 11 & 61 & 12 & 67 \\
\hline Asked if I had children and how old the youngest one was & 10 & 56 & 11 & 61 \\
\hline Asked if I wanted to have more children & 7 & 39 & 6 & 33 \\
\hline Asked when I wanted to have them & 2 & 11 & 4 & 24 \\
\hline Asked if I was using a contraceptive method & 3 & 17 & 6 & 35 \\
\hline Asked if I was satisfied with the method & 1 & 33 & 1 & 14 \\
\hline Asked if I wanted another method & 12 & 67 & 5 & 28 \\
\hline Asked me which contraceptive methods I knew about & 8 & 44 & 7 & 39 \\
\hline Asked me about the methods I had used in the past & 2 & 11 & 1 & 6 \\
\hline Asked the date of my last menstrual period & 4 & 22 & 3 & 17 \\
\hline Asked if I was menstruating & 7 & 39 & 7 & 39 \\
\hline
\end{tabular}

Table 5 indicates whether or not the intervention produced or diminished a bias that may affect a women's capacity to choose a method in a fully informed manner. Again, there was little difference before and afterwards, with a slight increase in the proportion of providers mentioning several methods, including the IUD. Combining the proportion of women who were asked which method they were interested in, and those that were themselves asked to choose a method, full informed choice was observed in nearly $90 \%$ of consultations; this practice did not change over time. In the remaining $10 \%$ of cases, the provider made a recommendation, asking the woman if she would like to use that method. It is important to note that both before and after the intervention, the IUD was the method most frequently mentioned by providers, suggesting that a better understanding of the client's individual needs was successful in helping providers and clients filter out methods less relevant for the set of circumstances presented.

Table 5: $\quad$ Contraceptive Options Presented by Providers

\begin{tabular}{|l|c|c|c|c|}
\hline \multirow{2}{*}{} & \multicolumn{4}{|c|}{ Period } \\
\cline { 2 - 5 } & \multicolumn{3}{|c|}{ Before } & \multicolumn{2}{c|}{ After } \\
\cline { 2 - 5 } & $\mathbf{N}$ & $\%$ & $\mathbf{N}$ & $\%$ \\
\hline Informed me of all methods available & 10 & 56 & 9 & 50 \\
\hline Described the cervical mucus method & 0 & 0 & 2 & 12 \\
\hline Described the pill & 5 & 28 & 10 & 59 \\
\hline Described the injectable & 7 & 39 & 11 & 65 \\
\hline Described the condom & 7 & 39 & 8 & 44 \\
\hline Described the IUD & 13 & 72 & 15 & 83 \\
\hline $\begin{array}{l}\text { After presenting options, asked which } \\
\text { method was interested in }\end{array}$ & 9 & 50 & 8 & 44 \\
\hline Asked me to choose a method & 8 & 44 & 7 & 39 \\
\hline
\end{tabular}


Once the service provider gave information on the different methods, the simulated client was instructed to express interest in the IUD and to record which information she received from the provider. Table 6 shows that providers described virtually all of the characteristics of the IUD more frequently after the intervention, suggesting that the training has improved their information giving skills.

Table 6: $\quad$ Information Given by the Service Provider on the IUD

\begin{tabular}{|l|c|c|c|c|}
\hline \multirow{2}{*}{} & \multicolumn{4}{|c|}{ Period } \\
\cline { 2 - 5 } & \multicolumn{2}{|c|}{ Before } & \multicolumn{2}{c|}{ After } \\
\cline { 2 - 5 } & $\mathrm{N}=18$ & $\%$ & $\mathrm{~N}=18$ & $\%$ \\
\hline IUD is plastic/copper device inserted in the uterus & 11 & 61 & 16 & 89 \\
\hline The copper T prevents pregnancy for up to 10 years & 9 & 50 & 15 & 83 \\
\hline The IUD's effectiveness was explained to me & 5 & 28 & 14 & 78 \\
\hline Was told how the IUD prevents pregnancy & 6 & 33 & 10 & 56 \\
\hline Was told the ideal period in which to insert the IUD & 12 & 67 & 13 & 72 \\
\hline Was informed of need for pelvic examination & 5 & 28 & 5 & 28 \\
\hline Was told the IUD does not protect against STIs/HIV & 1 & 6 & 4 & 22 \\
\hline Was told that to get pregnant, IUD be removed at clinic & 8 & 44 & 12 & 67 \\
\hline
\end{tabular}

Table 7 shows that one of the main deficiencies in care remains identification of possible contraindications for the method's use. Minimal questions were asked on most issues and the training did not improve this at all.

Table 7: Information Requested by the Service Provider to Identify IUD Contraindications

\begin{tabular}{|l|c|c|c|c|}
\hline \multirow{2}{*}{} & \multicolumn{3}{|c|}{ Period } \\
\cline { 2 - 5 } & \multicolumn{2}{|c|}{ Before } & \multicolumn{2}{|c|}{ After } \\
\cline { 2 - 5 } & $\begin{array}{c}\mathrm{N}=1 \\
8\end{array}$ & $\mathrm{~N}=18$ & $\%$ \\
\hline If I have or have had cervical cancer & 0 & 0 & 3 & 17 \\
\hline If I know of any masses or deformities in my uterus & 0 & 0 & 1 & 6 \\
\hline If my partner has more than one sexual partner & 4 & 22 & 2 & 11 \\
\hline If I have more than one sexual partner & 0 & 0 & 2 & 11 \\
\hline If I have undiagnosed vaginal bleeding & 2 & 11 & 1 & 6 \\
\hline If I have ulcers in the vulva or vagina & 0 & 0 & 1 & 6 \\
\hline If I have had a vaginal cytology sample & 2 & 11 & 2 & 11 \\
\hline If I have or have had pelvic inflammatory disease in the past three months & 0 & 0 & 0 & 0 \\
\hline If I have severe menstrual cramps & 0 & 0 & 0 & 0 \\
\hline If I have had an extra-uterine pregnancy & 0 & 0 & 0 & 0 \\
\hline If in the last three months I have had a septic miscarriage and did not & 0 & 0 & 0 & 0 \\
\hline receive treatment & 0 & & \\
\hline If I have heavy or purulent vaginal discharge, except HIV & 1 & 6 & 2 & 11 \\
\hline
\end{tabular}


Table 8 shows that, following the training, providers more frequently gave information on some of the elements related to the use of the IUD, such as making sure the IUD is in place and how to check the IUD strings.

Table 8: $\quad$ Information Given by the Service Provider Related to Use of the IUD

\begin{tabular}{|l|c|c|c|c|}
\hline \multirow{2}{*}{} & \multicolumn{4}{|c|}{ Period } \\
\cline { 2 - 5 } & \multicolumn{2}{|c|}{ Before } & \multicolumn{2}{c|}{ After } \\
\cline { 2 - 5 } & $\mathrm{N}=18$ & $\%$ & $\mathrm{~N}=18$ & $\%$ \\
\hline How the IUD is inserted & 12 & 67 & 13 & 72 \\
\hline How to know if the IUD is still in place & 2 & 11 & 9 & 50 \\
\hline How to check the IUD strings & 3 & 17 & 9 & 50 \\
\hline What hygienic precautions to take in order to do so & 1 & 6 & 2 & 11 \\
\hline How frequently I need to verify the IUD strings & 8 & 44 & 6 & 33 \\
\hline
\end{tabular}

Table 9 shows that the quality of information given on side effects and warning signs did not improve after the training. Several studies have shown a greater continuity of use for the method when service providers give this information to women, and so efforts must be made to improve this component.

Table 9: $\quad$ Information Given by the Service Provider on Side Effects and Warning Signs

\begin{tabular}{|l|c|c|c|c|}
\hline \multirow{2}{*}{} & \multicolumn{4}{|c|}{ Period } \\
\cline { 2 - 5 } & \multicolumn{2}{|c|}{ Before } & \multicolumn{2}{c|}{ After } \\
\cline { 2 - 5 } & $\mathrm{N}=18$ & $\%$ & $\mathrm{~N}=18$ & $\%$ \\
\hline Heavier period & 13 & 72 & 8 & 44 \\
\hline Increase in menstrual cramps & 7 & 39 & 5 & 28 \\
\hline $\begin{array}{l}\text { Suspect pregnancy or do not get period after } \\
\text { two months }\end{array}$ & 1 & 6 & 2 & 11 \\
\hline If I have foul-smelling vaginal discharge & 2 & 11 & 0 & 0 \\
\hline $\begin{array}{l}\text { If I have vaginal hemorrhage, heavier than a } \\
\text { menstrual period }\end{array}$ & 1 & 6 & 2 & 11 \\
\hline $\begin{array}{l}\text { If I have a high fever and pain in my lower } \\
\text { abdomen }\end{array}$ & 0 & 0 & 1 & 6 \\
\hline If I suspect the IUD came out & 1 & 6 & 1 & 6 \\
\hline
\end{tabular}

Table 10 shows that, before the intervention, providers more frequently gave information on the subsequent calendar of visits, while afterwards they handed out brochures more frequently. Although this material should have been given to all women in the experimental clinics, only one third of simulated clients received the IUD brochure. After the intervention, a slightly greater proportion of providers explained that the client could return when she wanted to change the method without this affecting her right to use the services. 
Table 10: Information for Follow-Up by the Provider

\begin{tabular}{|l|c|c|c|c|}
\hline \multirow{2}{*}{} & \multicolumn{4}{|c|}{ Period } \\
\cline { 2 - 5 } & \multicolumn{2}{|c|}{ Before } & \multicolumn{2}{c|}{ After } \\
\cline { 2 - 5 } & $\mathrm{N}=18$ & $\%$ & $\mathrm{~N}=18$ & $\%$ \\
\hline Checked if I had understood what s/he explained & 1 & 6 & 4 & 22 \\
\hline $\begin{array}{l}\text { Return the following month after period for checking } \\
\text { the threads }\end{array}$ & 7 & 39 & 5 & 28 \\
\hline I can then return each year for my regular exam & 10 & 56 & 6 & 35 \\
\hline To return if I have any doubt or problem & 4 & 22 & 5 & 28 \\
\hline $\begin{array}{l}\text { If I wish to get pregnant again, to return to have the } \\
\text { IUD removed }\end{array}$ & 8 & 44 & 8 & 44 \\
\hline Gave me brochures on family planning & 1 & 6 & 3 & 17 \\
\hline Gave me brochures on the IUD & 0 & 0 & 7 & 39 \\
\hline Wrote down the information in records & 10 & 56 & 11 & 61 \\
\hline $\begin{array}{l}\text { Explained that I can decide I do not want the method } \\
\text { after all and continue to receive the services }\end{array}$ & 0 & 0 & 4 & 22 \\
\hline
\end{tabular}

In conclusion, the simulated client measures show that introduction of the intervention did not produce biases in the delivery of family planning methods, nor did it limit free and informed choice of the users. There was, however, very little improvement in the quality of counseling provided.

\section{Demand for the IUD}

Table 11 tests the hypothesis as to whether the interventions had an impact on demand for the IUD. Clinics in the experimental group inserted nearly twice the mean monthly number of IUDs (2 .0) after the intervention than during the pre-intervention period (1.12), a statistically significant increase. In contrast, during the intervention period the control group clinics achieved only about one-half $(0.78)$ of the mean monthly number of IUD insertions that they had delivered in the pre-intervention period (1.72), a statistically significant decline. Furthermore, the table also shows that the mean number of monthly insertions in the control and experimental clinics was not significantly different in the pre-intervention period, indicating similarity in the clinic activities, but was significantly different in the intervention period.

There is no clear explanation for the substantial decline in the delivery of IUD services in the control group over such a short period of time. Possible reasons could include a focus on posthurricane recovery activities in these areas, and the transfer of EngenderHealth's regional facilitators from the project areas into new areas where training was being extended. 
Table 11: Total and mean monthly number of IUDs inserted by group and time period

\begin{tabular}{|c|c|c|c|c|c|c|c|}
\hline \multirow{3}{*}{ PERIOD } & \multicolumn{4}{|c|}{ GROUP } & \multirow{2}{*}{\multicolumn{3}{|c|}{$\begin{array}{c}\text { Differences between } \\
\text { experimental and control } \\
\text { groups }\end{array}$}} \\
\hline & \multicolumn{2}{|c|}{ EXPERIMENTAL } & \multicolumn{2}{|c|}{ CONTROL } & & & \\
\hline & TOTAL & MEAN & TOTAL & MEAN & TOTAL & MEAN & SIG \\
\hline October 2005 - May 2006 (post) & 294 & 2.00 & 125 & 0.78 & +169 & +1.22 & $P=.003$ \\
\hline January - September 2005 (pre) & 211 & 1.12 & 310 & 1.72 & -99 & -0.60 & $P=.117$ \\
\hline Before - after difference & +83 & +0.88 & -185 & -0.94 & & & $P=.014$ \\
\hline Significance & & $\mathrm{P}=.038$ & & $\mathrm{P}=.022$ & & & \\
\hline \multicolumn{8}{|c|}{ Controlling for seasonality } \\
\hline January - May 2006 & 185 & 1.76 & 56 & 0.56 & +129 & 1.20 & $\mathrm{P}<.001$ \\
\hline January - May 2005 & 95 & 0.90 & 202 & 2.02 & -107 & -1.12 & $\mathrm{P}=.074$ \\
\hline Before - after difference & +90 & +0.86 & -146 & -1.46 & & & $\mathrm{P}=.020$ \\
\hline Significance & & $P=.001$ & & $\mathrm{P}=.015$ & & & \\
\hline Note: & rce: He & $\begin{array}{l}\text { h Cente } \\
\text { significa }\end{array}$ & Service & $\begin{array}{l}\text { tatistics } \\
\text { nted in a }\end{array}$ & cases & & \\
\hline
\end{tabular}

How should these results be interpreted? On the one hand, the total number of IUDs provided by both experimental and control group health centers declined from 521 IUDs in the preintervention period to 419 in the intervention period. However, because an experimental design with random allocation was used, the control group can be considered as describing what happens in the system in the absence of the intervention. Without the intervention, therefore, we should have observed a decline for all health facilities from 521 insertions to 210 insertions, rather than to the 419 actually observed.

To control for possible seasonal effects in demand, Table 11 also compares demand for IUDs for the same period in 2005 and 2006, i.e. January - May. To a large degree, the same results are observed: a significant decrease in the monthly average number of IUDs inserted in controlgroup health centers (from 2.02 in 2005 to 0.56 in 2006) and a strong and significant increase in the experimental clinics, from 0.90 to 1.76 IUDs per month. Likewise, we observe that for all clinics the total number of IUDs provided decreased from 297 to 241, but that there was an increase in the experimental health centers from 95 to 185 insertions and a decrease in the control group clinics from 202 to 56.

As noted earlier, supervisors had identified three health centers in the control group and five in the experimental group that did not comply with the inclusion criteria. In the experimental group there were seven facilities that did not insert any IUDs during the pre-intervention period (January - September 2005), and of these, three continued without inserting any IUDs during the post-intervention period (October 05 - May 06), two inserted one IUD, and the other two inserted two or more IUDs. In the control group, four facilities did not insert any IUDs during the pre-intervention period and one inserted one IUD. Of these five facilities, three did not insert any IUDs, one inserted one and the other inserted four in the post-intervention period. This 
analysis suggests that non-compliance with the inclusion criteria and its effect on this outcome indicator was equally distributed among both groups.

In absolute terms, the increase in the monthly number of IUDs provided by each health center in the experimental group fluctuated between 0.86 and 0.88 IUDs per month, that is, between 10.32 and 10.56 IUDs per year. There are 1,108 health centers in Honduras (241 CESAMOS and 867 CESARES), and so, if successfully scaled up, the model could lead to an increase of around 11,500 new IUD users a year.

Table 12 analyzes the association between intensity of implementation and demand for IUD services. As explained, the methodology to determine the intensity of implementation led to seven clinics being assigned to each group of high, medium and low intensity. As can be seen, the facilities that implemented with greater intensity increased their monthly insertion averages by 1.27 IUDs, while those with medium or low intensity increased their monthly averages by less than 0.5 IUDs. However, when analyzing the full periods, the only statistically significant differences observed are the increase in IUD services in the high-intensity group and the decline in the control group. When the January-May periods are compared to control for seasonality, there is a significant increase in the number of IUDs provided by the low-intensity clinics, but not by the mid-intensity clinics. Thus, the results suggest an association between the intensity of IEC activities in clinics and the number of IUD services provided. A regression analysis showed that only clinics that had implemented the interventions with high intensity significantly increased the number of IUDs provided compared with the control group.

Table 12: Total number and monthly average of IUD insertions by time period, group and degree of intensity of the intervention

\begin{tabular}{|c|c|c|c|c|c|c|c|}
\hline \multirow{3}{*}{$\begin{array}{l}\text { INTENSITY/GROUP } \\
\text { Experimental Group }\end{array}$} & \multicolumn{7}{|c|}{ Full periods } \\
\hline & \multicolumn{2}{|c|}{$\begin{array}{l}\text { A } \\
\text { Jan } 2005 \text { - } \\
\text { September } 2005\end{array}$} & \multicolumn{2}{|c|}{$\begin{array}{l}\text { B } \\
\text { Oct } 2005- \\
\text { May } 2006 \\
\end{array}$} & \multicolumn{3}{|c|}{$\begin{array}{l}\text { B - A } \\
\text { Difference }\end{array}$} \\
\hline & $\mathbf{N}$ & $\mu$ & $\mathbf{N}$ & $\mu$ & $\mathbf{N}$ & $\mu$ & Signif \\
\hline -High & 147 & 2.33 & 202 & 3.60 & 55 & 1.27 & $P<0.001$ \\
\hline -Medium & 52 & 0.72 & 60 & 0.93 & 8 & 0.21 & $P=0.07$ \\
\hline -Low & 12 & 0.22 & 32 & 0.67 & 20 & 0.45 & $P=0.07$ \\
\hline Control Group & 310 & 1.72 & 125 & 0.78 & -185 & -0.94 & $P<0.01$ \\
\hline \multirow[b]{2}{*}{ INTENSITY/GROUP } & \multicolumn{7}{|c|}{ Controlling for seasonality } \\
\hline & \multicolumn{2}{|c|}{$\begin{array}{l}\text { D } \\
\text { Jan - May } 2005\end{array}$} & \multicolumn{2}{|c|}{$\begin{array}{l}\text { E } \\
\text { Jan - May } 2006\end{array}$} & \multicolumn{3}{|c|}{$\begin{array}{l}\text { E-D } \\
\text { Difference }\end{array}$} \\
\hline Experimental Group & $\mathbf{N}$ & $\mu$ & $\mathbf{N}$ & $\mu$ & $\mathbf{N}$ & $\mu$ & Signif \\
\hline -High & 56 & 1.60 & 140 & 4.00 & 84 & 2.4 & $P<0.024$ \\
\hline -Medium & 28 & 0.62 & 16 & 0.025 & -12 & -0.595 & $P=0.323$ \\
\hline -Low & 11 & 0.37 & 29 & 0.97 & 18 & 0.6 & $P<0.039$ \\
\hline Control Group & 202 & 2.02 & 56 & 0.56 & -146 & -1.46 & $P<0.011$ \\
\hline
\end{tabular}




\section{Socio-demographic characteristics of IUD Acceptors}

Service providers participating in this study were asked to fill in one project record for each client that requested the IUD during the intervention period. These records provided data on the socio-demographic characteristics of clients and the characteristics of care provided to the client. Appendix 3 presents a list of the data collected by the client record.

Table 13: Socio-demographic characteristics of women that accepted an IUD

\begin{tabular}{|c|c|c|}
\hline \multirow{2}{*}{ VARIABLE } & \multicolumn{2}{|c|}{ GROUP } \\
\hline & EXPERIMENTAL & CONTROL \\
\hline Age: & $N=250$ & $\mathrm{~N}=59$ \\
\hline-15 to 19 & 20 & 22 \\
\hline-20 to 29 & 56 & 49 \\
\hline - Over 30 & 23 & 29 \\
\hline - Average (Years) & 25 & 25 \\
\hline Years of schooling: & $\mathrm{N}=\mathbf{2 3 6}$ & $\mathrm{N}=50$ \\
\hline - $0-3$ years & 28 & 8 \\
\hline - 4-6 years & 51 & 70 \\
\hline - 7 or more & 20 & 22 \\
\hline Average & 5.5 & 6.5 \\
\hline Partner's years of schooling: & $\mathrm{N}=177$ & $\mathrm{~N}=37$ \\
\hline - $0-3$ years & 20 & 3 \\
\hline - 4-6 years & 63 & 70 \\
\hline - 7 or more & 17 & 17 \\
\hline Average & 5.8 & 6.8 \\
\hline Number of children & $\mathrm{N}=252$ & $\mathrm{~N}=59$ \\
\hline - Zero & 0 & 5 \\
\hline$-1-2$ & 54 & 61 \\
\hline$-3-5$ & 39 & 27 \\
\hline - 6 or more & 7 & 7 \\
\hline Average & 2.6 & 2.4 \\
\hline Age of youngest child & $\mathrm{N}=241$ & $\mathrm{~N}=55$ \\
\hline $\begin{array}{l}\text { - Less than one year old } \\
\text { - Breastfeeding } \\
\text { - Has got her menstrual period again }\end{array}$ & $\begin{array}{l}46 \\
87 \\
52\end{array}$ & $\begin{array}{l}46 \\
82 \\
27\end{array}$ \\
\hline - 1-4 years & 45 & 42 \\
\hline - 5-9 years & 8 & 7 \\
\hline - 10 or more & 2 & 6 \\
\hline Average & 1.76 & 2.05 \\
\hline
\end{tabular}


The intervention sought to increase knowledge of the IUD and especially among women in more isolated areas or living further away from the health center. To test this hypothesis, the admission records of 259 IUD users in the experimental group were compared with those of 59 IUD users in the control group after introduction of the intervention. These figures represent $88 \%$ and $47 \%$ of the samples in each group respectively; this difference is probably because the service providers in the experimental group understood that they were part of an intervention and so may have been motivated to keep more complete records than those in the control group.

Given the use of a randomized control design, in the absence of an intervention we would expect that the IUD clients in the experimental and control groups would have the same sociodemographic characteristics both before and after the intervention. Table 13 compares the characteristics of the two post-intervention groups. Women in both groups had an average age of slightly over 25 years. Women in the experimental group and their partners had significantly fewer years of schooling, and on average had a greater number of living children, with their youngest child at a younger age than those in the control group, although the probability of having a child of less than one year of age was similar for both groups. Women in the experimental group were more likely to be exposed to the possibility of becoming pregnant since they had started menstruating again. Other data not presented in the table showed that women in the experimental group took on average 14 more minutes longer those in the control group to reach the health center, and that almost three times as many took over an hour and a half on their trip, probably because more of them walked or biked; which may be the reason women in the experimental group had slightly lower expenses. These differences were not statistically significant.

Table 14: Contraceptive Use and Reproductive Ideals of women accepting an IUD

\begin{tabular}{|l|c|c|}
\hline \multirow{2}{*}{ VARIABLE } & \multicolumn{2}{c|}{ GROUP } \\
\cline { 2 - 3 } & EXP & CONTROL \\
\hline Proportion currently using contraception & $\mathbf{N}=\mathbf{2 5 2}$ & $\mathbf{N}=59$ \\
\hline - Rhythm / natural / withdrawal / collar & 1 & 2 \\
\hline - Exclusive breastfeeding & 1 & 2 \\
\hline - Pill & 10 & 5 \\
\hline - Injection (Depo-Provera $($ ) & 18 & 29 \\
\hline - Condom & 3 & 5 \\
\hline - IUD & 2 & 0 \\
\hline - None & 66 & 58 \\
\hline Total & 35 & 42 \\
\hline Has never used a method in the past & $26(\mathrm{n}=122)$ & $9(\mathrm{n}=33)$ \\
\hline Wishes to have more children in the future & $\mathrm{N}=254$ & $\mathrm{~N}=59$ \\
\hline - Yes & 52 & 56 \\
\hline - 0-2 years & 11 & 24 \\
\hline$\quad$ More than 2 years & 89 & 76 \\
\hline - No & 40 & 29 \\
\hline - I don't know & 8 & 15 \\
\hline
\end{tabular}


Table 14 shows that women in the experimental group were more likely than those in the control group to be already using a contraceptive method or to have never used a method when they requested an IUD. Moreover, women in the experimental group were more likely to not want to have more children in the future, and for those that did, they preferred to space for more than two years.

These findings suggest that the intervention messages tended to reach women and their partners with a lower level of schooling, who were less likely to use or have used contraception, and who were more likely to want to space or limit childbearing. This suggests that the communications strategy did succeed in reaching and attracting to services women with a greater need for services.

\section{Characteristics of care provided to IUD clients}

During training, service providers were asked to fill out a clinic history that provided information on the characteristics of the services provided, including whether or not an IUD had been inserted and why, and if inserted, how pregnancy had been ruled out. This form was then completed during the intervention period. It should be noted that the $\mathrm{MOH}$ had already introduced the pregnancy checklists developed by $\mathrm{FHI}^{4}$ as part of the previous OR project that had tested the strategy to expand the training of nurse auxiliaries (Mendoza and Vernon, 2001), and that EngenderHealth has continued training providers subsequently. In the training for this project, there was a refresher about the eligibility criteria for the IUD.

Table 15 shows that the most common method for ruling-out pregnancy was the presence of a menstrual period, and that this was much more likely to be done by providers in the experimental than control group. It is also surprising that, in both groups, pregnancy tests were rarely used in order to rule out pregnancy. At the time of the follow-up visit, women in the experimental group were more likely to report not experiencing any discomfort with the method; the most common discomforts were cramps, changes in bleeding and vaginal discharge. There were few differences between groups in terms of having doubts about the method or willingness to recommend the IUD to friends.

4 FHI. 2007. How to be reasonably sure a client is not pregnant. See:

http://www.fhi.org/en/RH/Pubs/servdelivery/checklists/pregnancy/index.htm 
Table 15: Characteristics of Care Provided to Women by Group

\begin{tabular}{|l|c|c|}
\hline \multirow{2}{*}{\multicolumn{1}{|c|}{ VARIABLE }} & \multicolumn{2}{c|}{ GROUP } \\
\cline { 2 - 3 } & EXPERIMENTAL & CONTROL \\
\hline Criterion used to rule out pregnancy: & $\mathbf{N}=\mathbf{2 4 6}$ & $\mathbf{N}=\mathbf{5 7}$ \\
\hline - Presence of menstrual period & 59 & 33 \\
\hline - Current use of injectable or other method & 9 & 23 \\
\hline - Exclusive breastfeeding six months post-partum & 17 & 18 \\
\hline - Gave birth in the past six weeks & 22 & 28 \\
\hline - Abortion/ miscarriage in the past seven days & 1 & 0 \\
\hline - No sexual relations since last menstrual period & 9 & 4 \\
\hline - Pregnancy test & 5 & 2 \\
\hline Characteristics at follow-up visit & & $\mathbf{N}=\mathbf{3 0}$ \\
\hline How she feels with the method: & $\mathbf{N}=\mathbf{1 4 0}$ & 83 \\
\hline - Very well or well & 86 & 17 \\
\hline - More or less or bad & 14 & $\mathbf{N}=\mathbf{2 8}$ \\
\hline Discomforts experienced: & $\mathbf{N}=\mathbf{1 3 9}$ & 32 \\
\hline - Cramps & 17 & 7 \\
\hline - Vaginal bleeding & 12 & 7 \\
\hline - Vaginal discharge & 6 & 54 \\
\hline - None & 66 & $7(\mathrm{n}=30)$ \\
\hline Percentage with doubts about the method & $10(\mathrm{n}=130)$ & $63(\mathrm{n}=\mathbf{3 0})$ \\
\hline Percentage recommended the method to friends & $67(\mathrm{n}=138)$ & \\
\hline
\end{tabular}

\section{Costs of the intervention}

The costs of the implementing the intervention can be categorized according to: training for staff and volunteers; design and reproduction of educational materials; time used for educational activities. Three workshops were held for facility personnel, facilitated by two MOH nurses and attended by 45 service providers and supervising personnel from the experimental clinics. Each workshop lasted one and a half days. The total cost of the workshops was \$5,267 (100,540 Lempiras). The equivalent of $\$ 5,262$ was spent on the design and reproduction of IEC materials, including \$1,806 for 100 manuals, \$237 for 25,000 flyers, \$589 for 5,000 brochures and \$2,630 for 1,000 posters. Health centers reported having trained a total of 263 volunteers in one-half day sessions at a cost of $\$ 4.73$ per volunteer ( $\$ 1.84$ for materials plus $\$ 2.89$ for a meal) for a total cost of $\$ 1,245$. In addition, three supervision visits were made by one central level supervisor and a driver to each project zone, each visit requiring ten days, for a total cost of $\$ 2,235$. Thus, the total direct cost of implementing the interventions was $\$ 14,036$.

Clinics in the experimental group inserted an additional 83 IUDs during the intervention period compared with the pre-intervention period; using this indicator, the cost per additional IUD 
provided was $\$ 169$. It should be recognized, however, that this cost analysis is incomplete, since no consideration is given to the equivalent contribution of the salary of supervisors, trainers, trainees and service providers, as well as the supervision costs at the zone level or the time used by providers to implement the strategy and deliver the IUD services. Thus, the results are merely illustrative of the additional costs that the Ministry of Health of Honduras would have per additional IUD provided.

\section{DISSEMINATION AND UTILIZATION}

Given the collaborative and participatory nature of this project, staff of the $\mathrm{MOH}$, ASHONPLAFA and EngenderHealth learned about the findings as they were produced, and so became well aware of the results. The MOH project monitors and EngenderHealth staff made presentations in all project sites and in all health areas that receive USAID support. A summary of project results was also widely distributed through supervisors visiting all service delivery outlets.

At the end of the project, additional copies of the project's IEC materials were printed and distributed in USAID-supported project areas, and supervisors motivated service delivery staff to implement the interventions, although no follow-up was made of the degree of implementation achieved. Qualitative information provided by the supervisors shows that a large proportion of service delivery units and health zones included this activity in their 2007 workplans, but given the decentralized nature of the $\mathrm{MOH}$ no data are available on the degree to which the activity was programmed or implemented. The results of this and other IUD OR projects were presented at the International Family Planning Workshop conducted in Guatemala on October 8-11, 2007.

\section{CONCLUSIONS AND RECOMMENDATIONS}

One of the main concerns when communicating messages focusing on a single method is the possibility that women might not be provided with complete information on a range of contraceptive methods, thereby possibly infringing their ability to make a free and informed choice that best suits their personal circumstances. In this project no bias in the counseling provided to simulated clients was found, indicating that messages about specific methods can be communicated within USAID-funded projects without violating conditions of the Tiahrt amendment if done in the context of a program that has provided comprehensive training in family planning counseling to service providers.

The high costs of the intervention were due to the training workshops and the small print runs of IEC materials. If the strategy were applied in a wider geographical area, costs would decrease by not having to cover the design of materials and by printing a greater number of copies at a lower cost per copy. Training of service delivery personnel could possibly be done in the context of routine supervision visits rather than in stand-alone training workshops.

The main conclusion is that communication of messages about a specific contraceptive method, while also communicating messages about other contraceptive methods, through printed 
materials (flyers, brochures and posters) and interpersonal messages (individual talks and counseling) by staff of health centers and volunteers in the community is effective in increasing demand for the method. The results also show that the strategy was effective in reaching those who live farther away from the health facilities and who have greater unmet needs for family planning.

\section{REFERENCES}

Akin, A.; R.H. Gray and R. Ramos. 1980. Training auxiliary nurse-midwives to provide IUD services in Turkey and the Philippines. Studies in Family Planning, Vol. 11, No. 5 (May), pp. 178-187.

Bang, Sook, S.W. Song and C. H. Choi. 1968. Improving access to the IUD: Experiments in Koyang, Korea. Studies in Family Planning, Vol. 1, No. 27 (March), pp. 4-11

ENESF 2001. Encuesta Nacional de Epidemiología y Salud Familiar (ENESF) 2001. Informe Resumido. Tegucigalpa, Honduras, Secretaría de Salud, ASHONPLAFA, USAID, CDC y MSH.

Eren, N; R. Ramos and R.H. Gray. 1983. Physicians vs. auxiliary nurse-midwives as providers of IUD services: a study in Turkey and the Philippines. Studies in Family Planning, Vol. 14, No. 2 (February), pp.43-47.

Martínez, Laura. May 2003. Informe de Consultoría. Evaluación de las Inserciones del IUD por Auxiliares de Enfermería de las Regiones 1, 2 y 5. Tegucigalpa, Honduras, EngenderHealth.

Mendoza, Irma and Ricardo Vernon. 2001 Promoción de Servicios de Salud Reproductiva en Comunidades Rurales de Honduras. Population Council, Programa Fronteras de la Salud Reproductiva, Tegucigalpa, Honduras, June 5, 2001.

Secretaría de Salud de Honduras. Unidad de Atención a la Mujer. 1999. Normas y Procedimientos. Manual para la Atención Integral de la Mujer. Secretaría de Salud de Honduras, Tegucigalpa, Honduras, September.

Villanueva, Yanira; L. Hernández, I. Mendoza and R. Lundgren. 1998. Expansión del Rol de las Auxiliares de Enfermería en la Oferta de Servicios de Planificación Familiar y la Toma de Muestras de Citología. Informe Final. INOPAL III, Tegucigalpa, Honduras, Population Council.

Villanueva, Yanira; I.Mendoza, C. Aguilar, S. M. Rodríguez and R.Vernon. 2001. Expansión del Rol de las Enfermeras Auxiliares en la Entrega de Servicios de Salud Reproductiva en Honduras. Informe Final de Investigación Operativa. Programa Fronteras de la Salud Reproductiva, Population Council, Tegucigalpa, Honduras, June 5, 2001. 


\section{APPENDICES}

\section{Appendix 1: Health Units Included in the Sample by Group, Department and Municipality}

\begin{tabular}{|c|c|c|c|c|c|}
\hline \multicolumn{3}{|c|}{ CONTROL } & \multicolumn{3}{|c|}{ EXPERIMENTAL } \\
\hline DEPARTMENT & MUNICIPALITY & HEALTH UNIT & DEPARTMENT & MUNICIPALITY & HEALTH UNIT \\
\hline Atlantida & La Masica & Cr.San Juan Benque & Atlántida & Jutiapa & Cr.Los Olanchitos \\
\hline Atlantida & La Masica & Cm.San Juan Pueblo & Atlántida & Jutiapa & Cm.Entelina \\
\hline Francisco Morazán & Ojojona & Cr.San Buena Vent. & Atlántida & Jutiapa & Cr.Nueva Armenia \\
\hline Francisco Morazán & Ojojona & Cr.Lacali & Atlántida & Jutiapa & Cr.Descombros \\
\hline Francisco Morazán & Ojojona & Cr.El Sauce & Atlántida & Jutiapa & Cr.Jutiapa \\
\hline Francisco Morazán & Ojojona & Cr.Montaña Izopo & Copán & Nueva Arcadia & Cm.La Entrada \\
\hline Francisco Morazán & Ojojona & Cm.Ojojona & Copán & Nueva Arcadia & Cr.Chalmeca \\
\hline Francisco Morazán & La Venta del Sur & Cr.La Venta del sur & Intibucá & Yamaranguila & Cm.Yamaranguila \\
\hline Francisco Morazán & Sabanagrande & Cm.Sabanagrande & $\mathrm{La} \mathrm{Paz}$ & $\mathrm{LaPaz}$ & Cr.Concepción \\
\hline Francisco Morazán & Santa Ana & Cm.Santa Ana & $\mathrm{LaPaz}$ & $\mathrm{La} \mathrm{Paz}$ & Cr.Yarumela \\
\hline Intibucá & La Esperanza & Cr San Rafael & $\mathrm{LaPaz}$ & $\mathrm{LaPaz}$ & Cm San José \\
\hline Intibucá & Jesús de Otoro & Cm Jesús de Otoro & $\mathrm{LaPaz}$ & Marcala & C.M.I Marcala \\
\hline Intibucá & La Esperanza & Cr San Jerónimo & Lempira & Erandique & CM Erandique \\
\hline Intibucá & La Esperanza & Cm.La Esperanza & Yoro & Olanchito & Cr.El Ocote \\
\hline Lempira & San Francisco & Cr Cruz Concordia & Yoro & Olanchito & Cr,El Nance \\
\hline Lempira & San Andrés & Cr.San Andres & Yoro & Olanchito & Cr.Carbajales \\
\hline Lempira & Lepaera & Cr.Jagua & Yoro & Olanchito & Cm.Carril \\
\hline Lempira & Lepaera & Cr.El Carmen & Yoro & Olanchito & Cr.Armenia \\
\hline Lempira & Lepaera & Cr.Ocotillo & Yoro & Olanchito & CMI.Tepusteca \\
\hline Lempira & Lepaera & Cm.Lepaera & Yoro & Olanchito & Cr.La Hicaca \\
\hline & & & Yoro & Olanchito & Cm.Olanchito \\
\hline
\end{tabular}




\section{Appendix 2: Simulated client profile and recording sheet}

\section{CONTACT WITH THE PROVIDER}

You will be given precise instructions about the provider you are to visit. Go to the

facility. If he or she is not there or is not in town, let your supervisor know as soon as you

can, until you get an interview.

\section{INTRODUCTION}

Tell the provider you are on the pill and have come for a check-up because you have had strong headaches recently. If the provider asks you for personal information or where you live in the community, tell her or him that you are just passing by and your discomfort led you to seek help. Be prepared to provide this information. If you are referred to someone else, tell the provider you wish he or she attend you.

\section{USER'S ROLE}

During the visit, limit yourself to responding the provider's questions. Do it according to the following profile:

You are a 32-year-old woman that does not wish to have children for the time being. You have been using the pill for the last five months, but your head is aching and you are scared. You have three children, the youngest is 11 months old and you do not breastfeed him anymore. You have been told that the headaches could be due to the pill, and you do not wish to use them anymore. You wish to find out more about other methods and do not know which the best one would be. The only other method you know is rhythm and you do not know if you want more children, but in any case you would like to wait at least 3 years before you get pregnant again. You are going to the Health Center for the first time because you have heard that they provide family planning there. When they explain the methods to you, show an interest in the IUD and wait to be given more information. If the provider does not mention the IUD, you will ask about the device. In the end, however, if the provider is ready to insert it, tell him or her you have to talk it over with your partner or husband, and that for the time being you'd rather take some condoms (if the provider does not suggest condoms until you decide to use the IUD, you will suggest them). You have not had a cytology sample and are menstruating. You have not had sexually transmitted diseases. You do not know if your husband will have problems using condoms. You also do not suspect that your husband has relations with other women.

\section{CHECKLIST}

Once the visit is over, when you are alone outside the health facility, pull out your checklist and fill it out immediately. 


\section{SIMULATED CLIENT CHECKLIST}

Health unit:

Provider: MD PN NA Other: specify

Name of provider:

Instructions: Complete this list when leaving the health establishment. Write down behaviors observed during consultation.

\begin{tabular}{|l|l|l|l|}
\hline$\#$ & QUESTION & WRITE DOWN \\
\hline INTERPERSONAL RELATIONS & Yes & No \\
\hline 101 & The provider introduced him or herself by name & & \\
\hline 102 & Counseling was on an individual basis & & \\
\hline 103 & The consultation was uninterrupted & & \\
\hline 104 & There were strangers listening to what I said & & \\
\hline 105 & There were strangers observing me & & \\
\hline 106 & The provider treated me politely & & \\
\hline 107 & I felt he or she showed an interest in my health & \\
\hline 108 & He or she seemed annoyed & \\
\hline NEEDS DIAGNOSIS & & \\
\hline 201 & He or she asked my age & & \\
\hline 202 & $\begin{array}{l}\text { He or she asked if I had children and the age of the } \\
\text { youngest }\end{array}$ & & \\
\hline 203 & Asked if I wanted to have more children & & \\
\hline 204 & Asked when I wished to have them & \\
\hline 205 & Asked me if I was using a contraceptive method & & \\
\hline 206 & Asked if I was satisfied with the method & & \\
\hline 207 & Why: & & \\
\hline 208 & Asked if I wished for another method & \\
\hline 209 & $\begin{array}{l}\text { Enquired regarding my knowledge of contraceptive } \\
\text { methods }\end{array}$ & & \\
\hline 210 & Asked about the methods I have used in the past & & \\
\hline 211 & $\begin{array}{l}\text { Asked why I had left the other method: } \\
\text { Rhythm } \\
\text { Injectable } \\
\text { Condom } \\
\text { Oral (the pill) }\end{array}$ & & \\
\hline METHOD OPTIONS & & \\
\hline 301 & Informed me of all available methods & & \\
\hline 302 & Described the cervical mucous method & & \\
\hline 303 & Described the pill & & \\
\hline 304 & Described injectables & & \\
\hline 305 & Described the condom & & \\
\hline 306 & Described the IUD & & \\
\hline 307 & $\begin{array}{l}\text { After presenting me with options, asked me which I was } \\
\text { interested in }\end{array}$ & & \\
\hline
\end{tabular}




\begin{tabular}{|c|c|c|c|}
\hline \multirow{2}{*}{\multicolumn{2}{|c|}{\begin{tabular}{|l|l}
$\#$ & QUESTION \\
After I answered the IUD,
\end{tabular}}} & \multicolumn{2}{|c|}{ WRITE DOWN } \\
\hline & & & \\
\hline 308 & Asked for the date of my last menstrual period & Yes & No \\
\hline 309 & Asked me if I was menstruating & & \\
\hline 310 & Asked me to choose a method & & \\
\hline \multicolumn{4}{|c|}{ ACTION MECHANISMS AND CHARACTERISTICS } \\
\hline 401 & $\begin{array}{l}\text { He or she told me that: } \\
\text { The IUD is a small plastic and copper device that is } \\
\text { inserted in the uterus }\end{array}$ & & \\
\hline 402 & The copper $T$ prevents pregnancies for up to ten years & & \\
\hline 403 & He or she explained the efficacy of the IUD to me & & \\
\hline 404 & Explained how the IUD prevents pregnancy & & \\
\hline 405 & Which is the ideal period in which to insert an IUD & & \\
\hline 406 & $\begin{array}{l}\text { That it is necessary to have a pelvic examination before } \\
\text { inserting the IUD }\end{array}$ & & \\
\hline 407 & That the IUD does not protect against STIs, HIV/AIDS & & \\
\hline 408 & $\begin{array}{l}\text { That if I wish to get pregnant, all I have to do is get the } \\
\text { IUD removed at a health facility }\end{array}$ & & \\
\hline \multicolumn{4}{|c|}{ CONTRAINDICATIONS. S/he ruled out... } \\
\hline 501 & Whether I have or have had cervical cancer & & \\
\hline 502 & $\begin{array}{l}\text { Whether I know whether I have any growths or } \\
\text { deformities in the uterus }\end{array}$ & & \\
\hline 503 & Whether my partner has multiple sex partners & & \\
\hline 504 & Whether I have multiple sex partners & & \\
\hline 505 & Whether I have undiagnosed vaginal bleeding & & \\
\hline 506 & Whether I have ulcers in the vulva or vagina & & \\
\hline 507 & Whether I have had a cytology sample taken & & \\
\hline 508 & $\begin{array}{l}\text { Whether I have or have had pelvic inflammatory disease } \\
\text { in the past three months }\end{array}$ & & \\
\hline 509 & Whether I have severe menstrual cramps & & \\
\hline 510 & Whether I have had an ectopic pregnancy & & \\
\hline 511 & $\begin{array}{l}\text { Whether in the past three months I had a septic } \\
\text { miscarriage and was not treated for it }\end{array}$ & & \\
\hline 512 & $\begin{array}{l}\text { Whether I have heavy or purulent vaginal discharge, } \\
\text { except HIV }\end{array}$ & & \\
\hline \multicolumn{4}{|c|}{ INSTRUCTIONS FOR USE. He or she told me ... } \\
\hline 601 & How the IUD is inserted & & \\
\hline 602 & How to know if the IUD is still in place & & \\
\hline 603 & How I can check the IUD's threads & & \\
\hline 604 & What hygiene precautions to take in order to do so & & \\
\hline 605 & How frequently I must verify the IUD strings & & \\
\hline \multicolumn{4}{|c|}{$\begin{array}{l}\text { SECONDARY EFFECTS AND WARNING SIGNALS } \\
\text { He or she told me it could cause discomfort such as: }\end{array}$} \\
\hline 701 & Heavier menstrual periods & & \\
\hline 702 & Increase in menstrual cramps & & \\
\hline
\end{tabular}




\begin{tabular}{|c|c|c|c|}
\hline \# & QUESTION & \multicolumn{2}{|c|}{ WRITE DOWN } \\
\hline \multicolumn{2}{|r|}{ That I must consult a health care provider immediately if: } & & \\
\hline 703 & $\begin{array}{l}\text { I suspect I am pregnant or do not get my period after two } \\
\text { months }\end{array}$ & & \\
\hline 704 & If I have foul-smelling vaginal discharge & & \\
\hline 705 & $\begin{array}{l}\text { If I have a vaginal hemorrhage, heavier than my } \\
\text { menstrual period }\end{array}$ & & \\
\hline 706 & If I have a high fever and pain in my lower abdomen & & \\
\hline 707 & If I suspect the IUD came out & & \\
\hline \multicolumn{2}{|c|}{ FOLLOW UP. He or she ... } & Yes & No \\
\hline 801 & $\begin{array}{l}\text { Verified if I had understood what she or he had explained } \\
\text { to me }\end{array}$ & & \\
\hline 802 & $\begin{array}{l}\text { Told me to return the following month, after my period, to } \\
\text { check the threads }\end{array}$ & & \\
\hline 803 & $\begin{array}{l}\text { Told me that after that I can come back every year for my } \\
\text { regular check-up }\end{array}$ & & \\
\hline 804 & Told me to return if I have any doubts or questions & & \\
\hline 805 & $\begin{array}{l}\text { Told me that if I wish to get pregnant again, I can return } \\
\text { when I wish to have the IUD removed }\end{array}$ & & \\
\hline 806 & Gave me family planning flyers & & \\
\hline 807 & Gave me IUD flyers & & \\
\hline 808 & Wrote down the information in the necessary forms & & \\
\hline 809 & $\begin{array}{l}\text { Explained to me that I could decide not to use the method } \\
\text { anymore at any time, and if this should happen, I could } \\
\text { continue to receive the health facility's services without a } \\
\text { problem. }\end{array}$ & & \\
\hline
\end{tabular}

OBSERVATIONS

\section{SUPERVISOR'S COMMENTS}




\section{Appendix 3: Questionnaire for Women accepting an IUD}

\section{IDENTIFICATION DATA}

Date of first visit:

Date of insertion:

Place where the client was attended:

day/ ___ month/ year

Type of provider that attended the client:

Number of devices inserted or removed in the past three months:

\section{CLIENT INFORMATION}

Age:

Woman's level of schooling:

Partner's level of schooling:

How many of your children currently live with you?

How old is your youngest child?

If your youngest child is under 1 year old:

Are you breastfeeding?

Has your menstrual period started again?

How long does it take you to come from your house to the Health Center?

What transport do you use in order to get here in that amount of time?

How much money did you spend in total today, including transportation, food and any other expense for having come to the Health Center and returned home?

How much time do you think you spent in total to come to the Health Center and go back home?

Did you have to take leave from a paid job or stop doing a gainful activity in order to come to the Health Center today?

Are you currently using a contraceptive method?

Which contraceptive method are you using?

Which contraceptive method(s) have you used in the past?

Do you wish to have more children in the future?

\section{RESULTS OF CARE}

CONTINUE VERIFYING ELIGIBILITY CRITERIA AND THEN COME BACK TO THIS

FORM TO ANSWER THESE TWO QUESTIONS:

Was the IUD inserted?

Which conditions were used to rule out pregnancy? (Check all that apply)

Why was the IUD not inserted?

\section{FOLLOW-UP AND CONTROL}

Date of visit:

Date of insertion: dayl

Inform the IUD user you will ask her questions regarding:

day/ ___ month/___ year

How do you feel with this method?

What discomforts have you experienced?

Do you have any doubts with regards to the method? Which doubt(s)?

Have you recommended the method to somebody?

Have you given flyers to friends? 


\section{Appendix 4: Educational activities by Experimental Clinic}

\begin{tabular}{|c|c|c|c|c|c|c|c|c|c|c|}
\hline \multirow{2}{*}{ Clinic } & \multirow{2}{*}{$\begin{array}{c}\text { Clients } \\
\text { informed }\end{array}$} & \multicolumn{3}{|c|}{$\begin{array}{l}\text { Distribution of IEC } \\
\text { Materials in Clinic }\end{array}$} & \multirow[t]{2}{*}{ Talk } & \multirow{2}{*}{$\begin{array}{l}\text { Volun- } \\
\text { teers } \\
\text { Trained }\end{array}$} & \multicolumn{3}{|c|}{$\begin{array}{c}\text { Distribution of } \\
\text { IEC materials by } \\
\text { Volunteers }\end{array}$} & \multirow{2}{*}{$\begin{array}{c}\text { Score / } \\
\text { Intensity }\end{array}$} \\
\hline & & Flyer & \begin{tabular}{|c|} 
Bro \\
chure
\end{tabular} & $\begin{array}{c}\text { Poste } \\
r\end{array}$ & & & Flyer & \begin{tabular}{|c|} 
Bro \\
chure
\end{tabular} & Poster & \\
\hline La Hicaca & 41 & 648 & 214 & 171 & 28 & 12 & 402 & 28 & 60 & 7.0 MED \\
\hline Concepción & 43 & 326 & 144 & 197 & 22 & 16 & 398 & 0 & 80 & 6.0 LOW \\
\hline San Jose & 88 & 0 & 0 & 122 & 30 & 0 & 0 & 0 & 0 & 5.0 LOW \\
\hline Los Olanchitos & 115 & 318 & 166 & 40 & 3 & 3 & 162 & 37 & 50 & 4.0 LOW \\
\hline Chalmeca & 135 & 839 & 184 & 82 & 13 & 0 & 254 & 54 & 85 & 5.0 LOW \\
\hline Carbajales & 142 & 553 & 180 & 145 & 44 & 0 & 528 & 58 & 268 & 6.5 LOW \\
\hline Descombros & 174 & 410 & 238 & 64 & 46 & 20 & 215 & 0 & 63 & 7.0 MED \\
\hline El Ocote & 176 & 547 & 238 & 124 & 24 & 9 & 543 & 0 & 345 & 7.5 MED \\
\hline El Nance & 191 & 363 & 85 & 30 & 17 & 3 & 0 & 0 & 45 & 6.0 LOW \\
\hline Nueva Armenia & 217 & 397 & 224 & 81 & 38 & 0 & 610 & 0 & 160 & $7.0 \quad$ MED \\
\hline \begin{tabular}{|l|} 
Jutiapa \\
\end{tabular} & 232 & 374 & 228 & 69 & 66 & 0 & 427 & 0 & 245 & 8.0 MED \\
\hline Entelina & 239 & 549 & 111 & 154 & 70 & 3 & 427 & 127 & 243 & $9.3 \mathrm{HIGH}$ \\
\hline Tepusteca & 258 & 813 & 172 & 200 & 51 & 36 & 376 & 66 & 235 & $9.7 \mathrm{HIGH}$ \\
\hline La Entrada & 270 & 1896 & 348 & 529 & 36 & 0 & 484 & 118 & 241 & 8.0 MED \\
\hline Yamranguila & 323 & 420 & 217 & 115 & 16 & 16 & 302 & 29 & 127 & $9.0 \quad$ MED \\
\hline Olanchito & 339 & 540 & 0 & 203 & 73 & 19 & 310 & 18 & 193 & 10.0 HIGH \\
\hline Erandi & 36 & 0 & 0 & 118 & 62 & 30 & 0 & 0 & 84 & 11.0 HIGH \\
\hline Yarumela & 43 & 744 & 88 & 56 & 23 & 4 & 476 & 150 & 380 & 8.3 MED \\
\hline Armeni & 436 & 832 & 231 & 167 & 168 & 14 & 15 & 25 & 3 & 10.0 HIGH \\
\hline El Carril & 496 & 677 & 207 & 185 & 60 & 12 & 120 & 40 & 71 & $10.0 \mathrm{HIGH}$ \\
\hline Marcala & 694 & 1108 & 239 & 416 & 140 & 61 & 0 & 0 & 80 & $12.0 \mathrm{HIGH}$ \\
\hline
\end{tabular}

